\title{
Effect of Propranolol on Ventricular Rate During Atrial Fibrillation in the Wolff-Parkinson-White Syndrome
}

\author{
FRED MORADY, LORENZO A. DICARLO, JR., \\ JEFFREY M. BAERMAN, and MICHAEL DE BUITLEIR \\ From the Division of Cardiology, Department of Internal Medicine, \\ University of Michigan Hospitals, Ann Arbor, Michigan
}

\begin{abstract}
MORADY, F., ET AL.: Effect of propranolol on ventricular rate during atrial fibrillation in the WolffParkinson-White syndrome. Atrial fibrillation was induced during an electrophysiology study in 10 patients with the Wolff-Parkinson-White (WPW) syndrome, after determination of baseline properties of the accessory atrioventricular $(A V)$ connection; intravenous propranolol $(0.2 \mathrm{mg} / \mathrm{kg})$ was then administered. Atrial fibrillation terminated during the drug infusion in three patients, allowing determination of propranolol's effects on conduction and refractoriness during sinus rhythm, before atrial fibrillation was reinduced. In these three patients propranolol had no effect on refractoriness or conduction properties of the accessory $A V$ connection during sinus rhythm. The mean ventricular rate during atrial fibrillation was slowed by $15-56$ beats/min in six patients, had no effect on the mean rate in three patients, and markedly increased the ventricular rate (203 to 267 beats $/ \mathrm{min}$ ) in one patient. In this patient, $54 \%$ of QRS complexes during atrial fibrillation were narrow, compared to $0-25 \%$ in the other patients. Propranolol reduced the percentage of QRS complexes that were narrow from $13 \pm 16 \%$ to $1 \pm 2 \%$ (mean \pm standard deviation, $p<0.05$ ). We conclude that propranolol may slow the ventricular rate during atrial fibrillation in some patients with the WPW syndrome, probably by blocking the effects of adrenergic activation. However, propranolol should not be used in patients with the WPW syndrome who have atrial fibrillation, if most QRS complexes during atrial fibrillation are preexcited. When a large percentage of QRS complexes are narrow, propranolol may increase the ventricular rate, probably by eliminating concealed retrograde conduction in the accessory AV connection. (PACE, Vol. 10, May, 1987)
\end{abstract}

Wolff-Parkinson-White syndrome, atrial fibrillation, propranolol

\section{Introduction}

Factors that influence ventricular rate during atrial fibrillation in the Wolff-Parkinson-White (WPW) syndrome include the refractory periods of the accessory atrioventricular (AV) connection and the AV node, concealed conduction in the accessory AV connection and the AV node, the ventricular refractory period, and the degree of adrenergic activation. ${ }^{1}$ Although propranolol has

Address for reprints: Fred Morady, M.D., Division of Cardiology, University of Michigan Hospital, UH/BI F245/0022, 1500 East Medical Center Drive, Ann Arbor, MI 48109-0022.

Received April 15, 1986; revision received August 29, 1986; accepted September 2, 1986. been shown to have no effects on accessory AV connection properties, ${ }^{2}$ its effect on the ventricular rate during atrial fibrillation in patients with the WPW syndrome has not been studied. By slowing conduction through the AV node and eliminating concealed retrograde conduction in the accessory AV connection, beta blockade could potentially increase the ventricular rate during atrial fibrillation. On the other hand, blockade of the effects of adrenergic activation on the accessory AV connection during atrial fibrillation might slow the ventricular rate.

The purpose of this study was to assess the effect of propranolol on ventricular rate during atrial fibrillation in patients with the WPW syndrome. 


\section{Methods}

The subjects in this study consisted of 10 patients with the WPW syndrome who underwent an electrophysiology study before undergoing surgical or transcatheter accessory pathway ablation. There were eight men and two women, with a mean age of $36 \pm 14$ years ( \pm one standard deviation). All patients had a history of recurrent orthodromic reciprocating tachycardia and five also had a history of atrial fibrillation, but no patient had a history of a cardiac arrest.

The electrophysiology studies were performed in the fasting, unsedated state after informed consent was obtained, and at least five halflives after discontinuation of all antiarrhythmic drugs. Electrode catheters were inserted into the femoral and subclavian veins and positioned in the right atrium, across the tricuspid valve for recording the His bundle electrogram, in the right ventricle and in the coronary sinus. The intracardiac electrograms and leads $\mathrm{V}_{1}$, I, and III were displayed on an oscilloscope and recorded on a Mingograph* 7 recorder. Pacing was performed with a programmable stimulator** at twice the diastolic threshold and with stimuli of $2 \mathrm{~ms}$ in duration.

Refractory periods were determined by the extrastimulus technique using a basic drive cycle length of $500 \mathrm{~ms}$. In two patients, determination of the anterograde effective refractory period of the accessory AV connection was limited by atrial refractoriness; in these patients, the accessory AV connection effective refractory period was designated as being less than the atrial functional refractory period.

After determination of baseline accessory AV connection properties, induction of orthodromic reciprocating tachycardia, and mapping of the accessory AV connection, atrial fibrillation was induced by right atrial pacing at cycle lengths between 150 and $50 \mathrm{~ms}$. After five minutes of atrial fibrillation, a one-minute recording was obtained. A $0.2 \mathrm{mg} / \mathrm{kg}$ dose of propranolol was then administered intravenously at a rate of $1 \mathrm{mg} / \mathrm{min}$. The blood pressure was measured with an arm cuff every one to two minutes during the infusion. Five minutes after completion of the drug infusion, an-

\footnotetext{
* Siemens-Elema AB, Solna, Sweden.

** Bloom Associates, Ltd., Narbeth, PA, USA.
}

other one-minute recording of atrial fibrillation was obtained. In three patients who reverted to sinus rhythm during the drug infusion, accessory AV connection properties were determined after the infusion was completed, before atrial fibrillation was reinduced. Seven patients remained in atrial fibrillation after administration of the propranolol, and they were then given $300-1,000 \mathrm{mg}$ of procainamide to convert the atrial fibrillation to sinus rhythm. Procainamide was administered in order to avoid the need for general anesthesia and direct current countershock. In these patients, the effects of propranolol on accessory AV connection conduction and refractoriness could not be determined. In one patient (\#5), the propranolol infusion was discontinued prematurely (after the administration of $5 \mathrm{mg}$ ) and procainamide was administered because of a marked acceleration in the ventricular rate.

The mean cycle length, the shortest cycle length between preexcited QRS complexes, the shortest cycle length between narrow $(\leq 0.08 \mathrm{~ms})$ QRS complexes, and the percentage of QRS complexes that were narrow were all determined from a one-minute recording of atrial fibrillation before and after the administration of propranolol. Statistical analyses were performed with either a paired or unpaired Student's $t$ test. P values $<0.05$ were considered significant.

\section{Results}

\section{Baseline Accessory AV Connection Characteristics}

The accessory AV connection was located in the left free wall in six patients and in the posterior septum in four patients. The shortest atrial pacing cycle length associated with 1:1 conduction through the accessory AV connection was $278 \pm 43$ $\mathrm{ms}$ (range $210-350 \mathrm{~ms}$ ). The mean anterograde refractory period of the accessory $\mathrm{AV}$ connection was $264 \pm 27 \mathrm{~ms}$ (range $<220-290 \mathrm{~ms}$ ).

\section{Effects of Propranolol on Atrial Fibrillation (Table I)}

The mean dose of propranolol administered was $13 \pm 4 \mathrm{mg}$. Propranolol was associated with a 5-10 $\mathrm{mmHg}$ drop in blood pressure in each patient. The mean ventricular rate during atrial fibrillation 
MORADY, ET AL.

Table I.

Effect of Propranolol on Atrial Fibrillation in Patients with the Wolff-Parkinson-White Syndrome

\begin{tabular}{|c|c|c|c|c|c|c|c|c|c|}
\hline \multirow[b]{2}{*}{ Patient } & \multirow[b]{2}{*}{$\begin{array}{l}\text { Propranolol } \\
\text { Dose (mg) }\end{array}$} & \multicolumn{2}{|c|}{ Mean Rate (bpm) } & \multicolumn{2}{|c|}{$\begin{array}{c}\text { SRR of } \\
\text { Preexcited QRS } \\
\text { Complexes (ms) }\end{array}$} & \multicolumn{2}{|c|}{$\begin{array}{l}\text { SRR of Narrow } \\
\text { QRS Complexes } \\
\text { (ms) }\end{array}$} & \multicolumn{2}{|c|}{$\begin{array}{l}\text { \% Narrow QRS } \\
\text { Complexes }\end{array}$} \\
\hline & & $\begin{array}{l}\text { Base- } \\
\text { line }\end{array}$ & $\begin{array}{l}\text { Pro- } \\
\text { pranolol }\end{array}$ & $\begin{array}{l}\text { Base- } \\
\text { line }\end{array}$ & $\begin{array}{c}\text { Pro- } \\
\text { pranolol }\end{array}$ & $\begin{array}{l}\text { Base- } \\
\text { line }\end{array}$ & $\begin{array}{c}\text { Pro- } \\
\text { pranolol }\end{array}$ & $\begin{array}{c}\text { Base- } \\
\text { line }\end{array}$ & $\begin{array}{c}\text { Pro- } \\
\text { pranolol }\end{array}$ \\
\hline 1 & 16 & 209 & 153 & 200 & 260 & - & 480 & 1 & 4 \\
\hline 2 & 17 & 196 & 187 & 240 & 280 & 一 & - & 0 & 0 \\
\hline 3 & 12 & 162 & 158 & 320 & 330 & 360 & - & 8 & 0 \\
\hline 4 & 15 & 180 & 150 & 230 & 250 & 310 & - & 16 & 0 \\
\hline 5 & 5 & 203 & 267 & 170 & 170 & 260 & - & 54 & 1 \\
\hline 6 & 16 & 189 & 165 & 180 & 230 & - & - & 1 & 2 \\
\hline 7 & 15 & 148 & 157 & 250 & 210 & 430 & - & 8 & 0 \\
\hline 8 & 12 & 164 & 128 & 240 & 270 & 320 & - & 16 & 4 \\
\hline 9 & 12 & 160 & 145 & 220 & 260 & 430 & - & 2 & 0 \\
\hline 10 & 8 & 168 & 140 & 250 & 280 & 360 & - & 25 & 3 \\
\hline
\end{tabular}

Abbreviations: $\mathrm{bpm}=$ beats/minute; $\mathrm{SRR}=$ shortest $\mathrm{RR}$ interval.

among the 10 patients was not significantly different after propranolol ( $165 \pm 39$ beats $/ \mathrm{min}$ ) as compared to baseline $(178 \pm 20$ beats $/ \mathrm{min} ; \mathrm{p}>0.05)$.

The individual responses of the ventricular rates to propranolol are shown in Figure 1. The ventricular rate during atrial fibrillation increased markedly in one patient, remained within 10 beats/min of the baseline ventricular rate in three patients, and decreased by $15-56$ beats/ $\mathrm{min}$ in the remaining six patients.

The shortest R-R interval between preexcited QRS complexes after propranolol (254 $\pm 44 \mathrm{~ms})$ was significantly longer than in the baseline state $(230 \pm 42 \mathrm{~ms} ; \mathrm{p}<0.05)$. The shortest R-R interval between narrow QRS complexes was $353 \pm 63 \mathrm{~ms}$ in the baseline state. After propranolol, only one patient had two consecutive narrow QRS complexes and the R-R interval between the narrow QRS complexes was $480 \mathrm{~ms}$. The percentage of QRS complexes that were narrow after propranolol $(1 \pm 2 \%)$ was significantly lower than in the baseline state $(13 \pm 16 \% ; p<0.05)$.

Comparing the six patients in whom propranolol slowed the ventricular rate during atrial fibrillation by $>15$ beats $/ \mathrm{min}$ with the other four patients, there were no significant differences in the baseline mean cycle length during atrial fibrillation, the shortest R-R interval between preexcited QRS complexes, the percentage of QRS complexes that were narrow, or the anterograde refractory period of the accessory AV connection.

The one patient (\#5) who had a marked increase in ventricular rate during atrial fibrillation after $5 \mathrm{mg}$ of propranolol had, in the baseline state, the shortest minimum $\mathrm{R}-\mathrm{R}$ interval between preexcited and narrow QRS complexes of all 10 patients, and the highest percentage of narrow QRS complexes (54\%).

\section{Effects of Propranolol on Accessory AV Connection Properties}

In patients \#3, 4, and 10 , accessory AV connection conduction and refractoriness could be measured before and after propranolol. The shortest atrial pacing cycle length associated with 1:1 conduction through the accessory AV connection (290 $\pm 26 \mathrm{~ms}$ ) was unchanged after propranolol $(280 \pm 10 \mathrm{~ms})$, as was the anterograde effective refractory period of the accessory AV connection $(277 \pm 12 \mathrm{~ms}$ baseline vs. $273 \pm 6 \mathrm{~ms}$ after propranolol).

\section{Discussion}

This study demonstrates that there is a heterogeneous response when intravenous propran- 


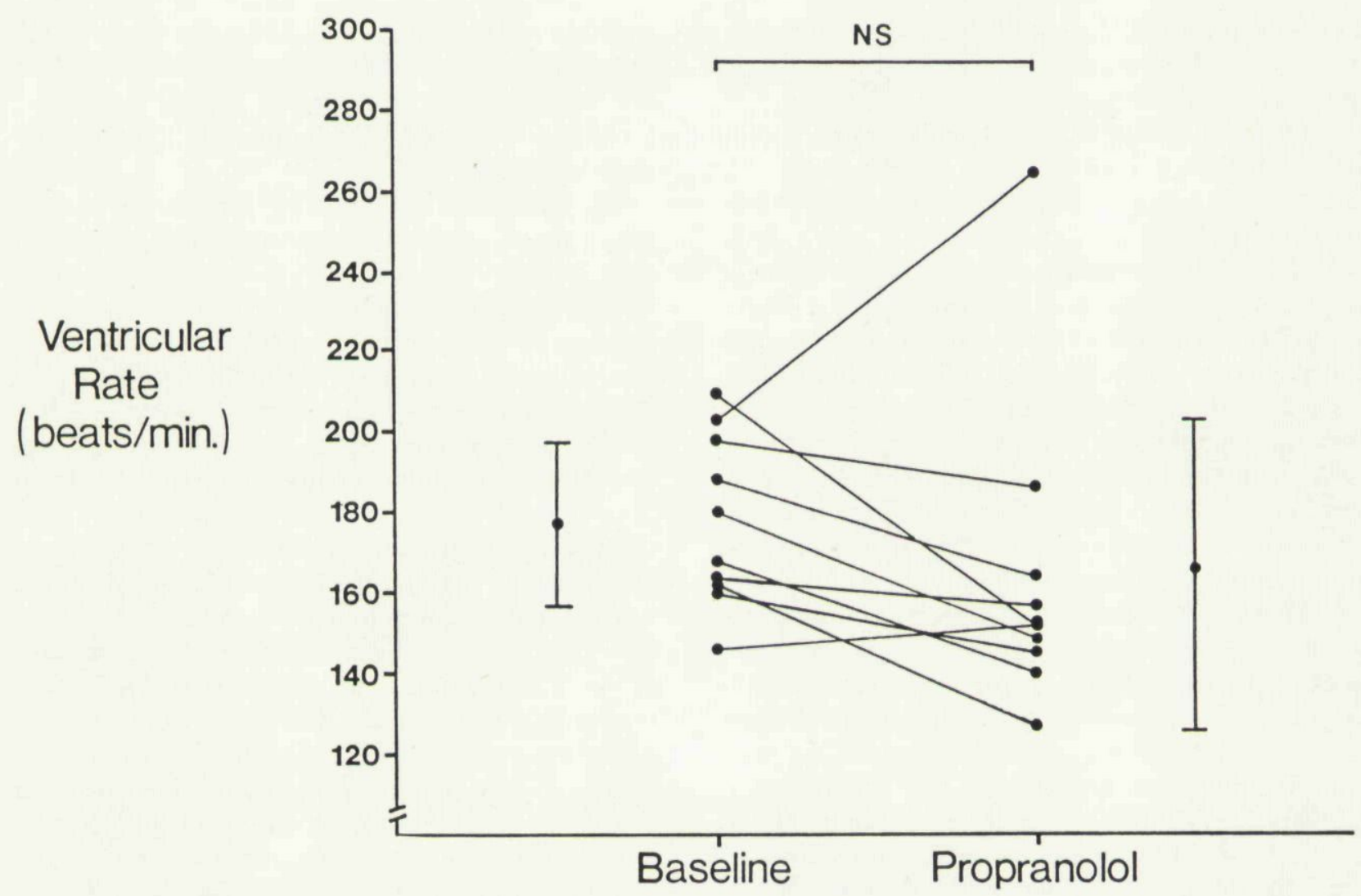

Figure 1. The effect of propranolol on ventricular rate during atrial fibrillation in patients with the Wolff-Parkinson-White syndrome. Shown are the mean \pm standard deviation and the individual ventricular rates before and after propranolol. Abbreviation: NS = not significant.

olol is administered during atrial fibrillation in patients who have the WPW syndrome. Although the average ventricular rate during atrial fibrillation usually is decreased by beta blockade, in some patients the average ventricular rate may remain unchanged or may increase markedly.

Despite the fact that propranolol resulted in a lengthening of the shortest $R-R$ interval between preexcited QRS complexes and in several patients slowed the mean ventricular rate during atrial fibrillation, no direct effect of propranolol on accessory AV connection properties could be demonstrated during sinus rhythm. Although accessory AV connection properties were determined before and after propranolol in only three patients in this study, Denes et al., in a much larger series of 18 patients, also demonstrated that propranolol has no effects on accessory AV connection conduction or refractoriness during sinus rhythm. ${ }^{2} \mathrm{~A}$ possible explanation for these apparently inconsistent observations is that anxiety and/or hypotension during atrial fibrillation results in adrenergic activation which in turn results in a shortening of accessory AV connection refractoriness and acceleration of the ventricular response. Consistent with this explanation is the observation that exogenous catecholamines shorten the accessory AV connection effective refractory period and increase the ventricular rate during atrial fibrillation in patients with the WPW syndrome. ${ }^{3-5}$ Svinarich et al. demonstrated that the effects of isoproterenol on accessory AV connection effective refractory period during sinus rhythm are reversed by intravenous propranolol. ${ }^{6}$ Beta blockade might therefore also reverse the effects of adrenergic activation and slow the ventricular response during atrial fibrillation. The absence of excess adrenergic activation during sinus rhythm may explain why no 
effects of propranolol on conduction or refractoriness were demonstrated either in this study or in the study of Denes et al. ${ }^{2}$

Of note is that the ventricular rate during atrial fibrillation accelerated markedly from 203 to 267 beats/min in one patient. This patient differed from the other patients in that more than half of the QRS complexes during atrial fibrillation were not preexcited, and the minimum R-R interval between narrow QRS complexes $(260 \mathrm{~ms})$ and also between preexcited QRS complexes (170 $\mathrm{ms}$ ) was quite short. After propranolol, only $1 \%$ of QRS complexes were narrow. By depressing conduction in the AV node, propranolol may have eliminated retrograde concealed conduction in the accessory AV connection, resulting in acceleration of the ventricular rate.

This mechanism has also been postulated to occur in response to intravenous verapamil in patients with the WPW syndrome who have both narrow and preexcited QRS complexes during atrial fibrillation. ${ }^{7}$ However, in contrast to propranolol, intravenous verapamil also results in an acceleration of the ventricular rate during atrial fibrillation even when most QRS complexes during atrial fibrillation are preexcited. ${ }^{7}$ This has been explained by intravenous verapamil's peripheral vasodilating effect, which causes a fall in blood pressure and a reflex increase in adrenergic tone. Although intravenous propranolol was associated with $5-10 \mathrm{mmHg}$ drop in blood pressure in the

\section{References}

1. Wellens HJJ, Durrer D. Wolff-Parkinson-White syndrome and atrial fibrillation. Relation between refractory period of accessory pathway and ventricular rate during atrial fibrillation. Am J Cardiol 1974; 34:777.

2. Denes P, Cummings JM, Simpson R, et al. Effects of propranolol on anomalous pathway refractoriness and circus movement tachycardias in patients with preexcitation. Am J Cardiol 1978; 41:1061.

3. Wellens HJJ, Brugada P, Roy D, et al. Effect of isoproterenol on the anterograde refractory period of the accessory pathways in patients with the WolffParkinson-White syndrome. Am J Cardiol 1984; 50: 180.

4. Cosio FG, Benson DW, Anderson RW, et al. Onset of atrial fibrillation during antidromic tachycardia: patients in this study, beta blockade presumably prevented the acceleration in conduction through the accessory AV connection which may have otherwise occurred with a reflex increase in adrenergic tone.

A limitation of this study is that serial plasma propranolol concentrations were not measured and therefore it is not known whether a steadystate plasma propranolol concentration was present during the observation period.

In conclusion, despite the absence of direct effects on accessory AV connection properties during sinus rhythm, propranolol may slow the ventricular response during atrial fibrillation in patients with the WPW syndrome, probably by reversing the effects on the accessory AV connection of adrenergic activation. The results of this study suggest that propranolol can be used safely in patients with the WPW syndrome who have episodes of atrial fibrillation, but only if most QRS complexes during atrial fibrillation are preexcited. If a large percentage of QRS complexes during atrial fibrillation are narrow, propranolol may result in a marked acceleration in the ventricular rate, probably by eliminating concealed retrograde conduction in the accessory AV connection.

Acknowledgment: The authors thank Mrs. Lisa Hackbarth for her secretarial assistance.

Association with sudden cardiac arrest and ventricular fibrillation in a patient with Wolff-Parkinson-White syndrome. Am J Cardiol 1982; 50:353.

5. German LD, Gallagher JJ, Broughton A, et al. Effects of exercise and isoproterenol during atrial fibrillation in patients with the Wolff-Parkinson-White syndrome. Am J Cardiol 1983; 51:1203.

6. Svinarich JT, Tai DY, Sung RJ. Is beta-adrenergic blockade contraindicated in Wolff-Parkinson-White patients prone to atrial fibrillation? (abstr) Circulation 1984; 70(Supp II):II-251.

7. Gulamhusein S, Ko P, Carruthers SG, et al. Acceleration of the ventricular response during atrial fibrillation in the Wolff-Parkinson-White syndrome after verapamil. Circulation 1982; 65:348. 
This document is a scanned copy of a printed document. No warranty is given about the accuracy of the copy. Users should refer to the original published version of the material. 